\title{
Stress among medical doctors working in public hospitals of the Ngaka Modiri Molema district (Mafikeng health region), North West province, South Africa
}

I Govender, MB BCh, MBA, MMed, FCFP, DOH, Dip HIV/AIDS

Department of Family Medicine and Primary Health Care, Faculty of Health Science, University of Limpopo (Medunsa Campus), Pretoria

E Mutunzi, MD

Mafikeng Provincial Hospital, North West

H I Okonta, MD, DHSM, MMed (Fam Med)

Department of Family Medicine and Primary Health Care, Faculty of Health Science, University of Limpopo (Medunsa Campus), Pretoria

Introduction. Stress and burnout are common among healthcare professionals, including doctors and nurses. Work-related stress rates among the general working population average $18 \%$, while among doctors the rate is reported to be around $28 \%$. Stress in doctors can result in multiple negative consequences. Detecting stress early may have positive outcomes for doctors, their families and the patients they care for. There is growing concern about stress in doctors working in public hospitals, yet there is a paucity of studies on stress among these doctors in South Africa.

Methods. A cross-sectional, descriptive study using a selfadministered, standardised questionnaire (12-item General Health Questionnaire (GHQ-12)) was conducted among medical doctors working in four hospitals of the Ngaka Modiri Molema (NMM) district, North West province. The research questionnaire was distributed and returned anonymously to ensure confidentiality.

Results. Of the 67 doctors in the study, 34 (51\%) were found to be stressed; 18 (27\%) of the participants were highly stressed (morbidly stressed). This result was compared with figures obtained by Govender in an earlier study conducted among private general practitioners in KwaDukuza, KwaZulu-Natal, in which $38 \%$ were stressed according to the GHQ-12; $23 \%$ of the subjects were morbidly stressed.

Conclusion. The rate of stress among doctors working in the four hospitals of the NMM district is higher than that found in other studies, which report a stress prevalence of $28-38 \%$ among doctors.

SAfr J Psych 2012;18(2):42-46.
Most people spend most of their awake hours at work.' Work may generate emotional, mental and/or physical disturbances in many people, and the quality and nature of people's experience at work may therefore have major health implications. Demanding or frustrating work or an inability to cope with stressors at work can have various short- and long-term effects.' These effects can be physical, mental or physiological (e.g. increased blood pressure, cardiovascular diseases), psychological/emotional (e.g. tenseness, anxiety disorders) or behavioural (e.g. alcohol abuse). 'This specific response of the body to all nonspecific demands is commonly called stress. $^{2}$

Defining stress is a challenge. Perceptions, attitudes, cultural backgrounds, academic theories and operational approaches all have a bearing on the way stress is defined. ${ }^{3}$ Furthermore, definitions vary a great deal from country to country and from one situation to another. ${ }^{4}$ For the purpose of this study, work stress is defined as the physical and emotional response that occurs when the requirements of the job do not match the capabilities, resources or needs of the employee. ${ }^{5}$

Robbins defined stress as a dynamic condition in which the individual is confronted with an opportunity, constraint or demand related to what he or she desires and for which the outcome is perceived to be both uncertain and important. ${ }^{6}$ Richards defines stress as the three-way relationship between demands on a person, that person's feelings about those demands, and their ability to cope with those demands?

Are doctors any different from the general working population? It may be surprising to laypeople that not every doctor is happy in his or her professional life. Stress and burnout (which is an extreme response to stress) among health care professionals, including doctors and nurses, are among the highest of all professions., ${ }^{8,9}$ 
The prevalence of stress among the general working population is around $18 \%$, while among doctors it is $28 \% .^{10}$

The modern medical workplace is a stressful place. ${ }^{11}$ It is a complex environment in which doctors continually have to learn new skills." Stress also arises from long hours, constantly caring for ill people, facing death of people they have come to know, and knowing that their occupation carries enormous responsibility and that people's lives depend on them. ${ }^{9-11}$ Other factors are fatigue; high demands on time interfering with doctors' other responsibilities; work conflicting with doctors' personal lives; dealing with emergencies; uncertainty and error; patient consumerism; increasing demands from patients; financial pressures; information overload; administration; and personality factors.9-11 It has been emphasised that stress levels are highest among doctors caring for terminally and chronically ill patients. ${ }^{12}$ Doctors also have to deal with stress from litigation threats.

This stress experienced by doctors results in high rates of marital problems, which sometimes end in divorce, 10,12 physical illness, social isolation, ${ }^{10,12}$ decreasing satisfaction with work, ${ }^{10,12}$ suicide, ${ }^{13}$ substance abuse and depression. ${ }^{14}$

There is growing concern about stress among public hospital doctors. The aim of this study was to ascertain the prevalence and the level of stress among doctors in the Ngaka Modiri Molema (NMM) district, North West province; to establish the relationship if any, between stress and working conditions; and to compare the results with findings of a study done among general practitioners in a private practice.

\section{Methods \\ Research design}

A cross-sectional study using a standardised questionnaire was carried out among medical doctors working in four hospitals in the NMM district from 5 March to 21 April 2010. The 12-item General Health Questionnaire (GHQ-12), designed and validated by the World Health Organization, was used to measure the presence and level of stress among the doctors. The measurement instrument was a standardised, anonymous questionnaire in English, and participation was voluntary. The GHQ-12 is used by researchers in various fields, including occupational health, and by clinicians to screen for psychiatric disorders. ${ }^{15}$ It is a validated questionnaire with high sensitivity that has been widely used to screen populations for stress. ${ }^{15}$ It is a short questionnaire with 12 questions and 3-point Likert scale responses for each question. We considered ease of completion important, since doctors are usually busy and may not take the time to complete a long questionnaire. The GHQ-12 yielded an overall total score. ${ }^{16}$ The score was then used to gauge whether each doctor was not stressed (total $<16$ ), was stressed (total 16 - 20) or had severe psychological stress (total $>20$ ). ${ }^{16}$ The questionnaire was modified slightly to exclude the name of the doctor and to include age group, hours per working week, length of time in practice and a general self-perception of whether the doctor was stressed or not. The cover page of the questionnaire explained the purpose of the study and gave the contact details of the researcher. Distribution and collection of the questionnaires were done anonymously to improve the truthfulness of the responses. Ethical approval for the study was obtained from the Medunsa Research and Ethics Committee (MREC), project number MREC/M/17/2009:PG. Permission to conduct the study was also obtained from managers in the NMM district.

The data were analysed using statistical software SPSS 17.0. A variety of statistical analyses were applied to the data, including crosstabulation and analysis of variance (ANOVA). Duncan's post hoc test was applied to establish relationships between stress and working conditions.

The overall Cronbach's alpha coefficient for all the items in the instrument was 0.847, which made the study instrument reliable. A pilot study was conducted on 18 February among 10 doctors currently working in another district hospital (Vryburg Hospital) outside the NMM district, to test the practicability of the research.

\section{Results}

There were 67 doctors who participated in this study. Table 1 shows that all age groups were represented, with the majority of subjects (78\%) below 45 years of age. A large proportion of the doctors worked more than the average 40-hour week (overtime work), they had varying years of experience, and the majority (87\%) did afterhours work.

Table 1. Age group, average hours worked by doctors per week, length of practice and after-hours calls

\begin{tabular}{|c|c|c|}
\hline & Frequency & $\%$ \\
\hline \multicolumn{3}{|c|}{ Age group (years) } \\
\hline $26-35$ & 32 & 48 \\
\hline $36-45$ & 20 & 30 \\
\hline $46-55$ & 9 & 13 \\
\hline$>55$ & 6 & 9 \\
\hline \multicolumn{3}{|c|}{ Average hours worked per week } \\
\hline$<30$ & 3 & 5 \\
\hline $31-50$ & 32 & 48 \\
\hline $51-70$ & 16 & 23 \\
\hline $71-90$ & 11 & 16 \\
\hline$>90$ & 5 & 8 \\
\hline \multicolumn{3}{|c|}{ Length of practice (years) } \\
\hline$<5$ & 21 & 31 \\
\hline $5-9.9$ & 19 & 28 \\
\hline $10-15$ & 8 & 12 \\
\hline$>15$ & 19 & 28 \\
\hline \multicolumn{3}{|c|}{ After-hours calls } \\
\hline No & 9 & 13 \\
\hline Yes & 58 & 87 \\
\hline
\end{tabular}




\section{Table 2. Responses to the GHQ-12 questionnaire}

\begin{tabular}{|c|c|c|}
\hline GHQ-12 questions & Frequency & $\%$ \\
\hline \multicolumn{3}{|c|}{ Able to concentrate on what you are doing } \\
\hline Better than usual $(0)^{*}$ & 6 & 9 \\
\hline Same as usual (1) & 29 & 43 \\
\hline Less than usual (2) & 29 & 43 \\
\hline Much less than usual (3) & 3 & 5 \\
\hline \multicolumn{3}{|l|}{ Lost much sleep due to worry } \\
\hline Not at all (0) & 9 & 13 \\
\hline No more than usual (1) & 30 & 45 \\
\hline Rather more than usual (2) & 16 & 24 \\
\hline Much more than usual (3) & 12 & 18 \\
\hline \multicolumn{3}{|c|}{ Felt that you are playing a useful part in your job } \\
\hline More than usual (0) & 28 & 42 \\
\hline Same as usual (1) & 23 & 34 \\
\hline Less than usual (2) & 13 & 19 \\
\hline Much less than usual (3) & 3 & 5 \\
\hline \multicolumn{3}{|c|}{ Felt capable of making decisions in your job } \\
\hline More than usual (0) & 18 & 27 \\
\hline Same as usual (1) & 35 & 52 \\
\hline Less than usual (2) & 13 & 19 \\
\hline Much less than usual (3) & 1 & 2 \\
\hline \multicolumn{3}{|c|}{ Felt that you were constantly under strain } \\
\hline More than usual (0) & 6 & 9 \\
\hline Same as usual (1) & 13 & 20 \\
\hline Less than usual (2) & 29 & 43 \\
\hline Much less than usual (3) & 19 & 28 \\
\hline \multicolumn{3}{|c|}{ Felt that you couldn't overcome difficulties } \\
\hline Not at all (0) & 12 & 18 \\
\hline No more than usual (1) & 31 & 46 \\
\hline Rather more than usual (2) & 20 & 30 \\
\hline Much more than usual (3) & 4 & 6 \\
\hline \multicolumn{3}{|c|}{ Been able to enjoy your normal day-to-day activities } \\
\hline More than usual (0) & 7 & 10 \\
\hline Same as usual (1) & 19 & 28 \\
\hline Less than usual (2) & 24 & 36 \\
\hline Much less than usual (3) & 17 & 25 \\
\hline \multicolumn{3}{|c|}{ Been able to face up to your problems } \\
\hline More than usual (0) & 6 & 9 \\
\hline Same as usual (1) & 32 & 48 \\
\hline Less than usual (2) & 25 & 37 \\
\hline Much less than usual (3) & 4 & 6 \\
\hline \multicolumn{3}{|c|}{ Been feeling unhappy or depressed } \\
\hline Not at all (0) & 6 & 9 \\
\hline No more than usual (1) & 21 & 31 \\
\hline Rather more than usual (2) & 26 & 39 \\
\hline Much more than usual (3) & 14 & 21 \\
\hline \multicolumn{3}{|c|}{ Been losing confidence in yourself } \\
\hline Not at all (0) & 25 & 37 \\
\hline No more than usual (1) & 29 & 43 \\
\hline Rather more than usual (2) & 12 & 18 \\
\hline Much more than usual (3) & 1 & 2 \\
\hline \multicolumn{3}{|c|}{ Been thinking of yourself as a worthless person } \\
\hline Not at all (0) & 47 & 70 \\
\hline No more than usual (1) & 12 & 18 \\
\hline Rather more than usual (2) & 7 & 11 \\
\hline Much more than usual (3) & 1 & 2 \\
\hline \multicolumn{3}{|c|}{ Been feeling reasonably happy with your job } \\
\hline More than usual (0) & 6 & 9 \\
\hline Same as usual (1) & 26 & 39 \\
\hline Less than usual (2) & 20 & 30 \\
\hline Much less than usual (3) & 15 & 22 \\
\hline
\end{tabular}

Table 2 sets out the responses to the 12 individual questions in the GHQ-12. Of NMM district doctors, 34 (51\%) scored more than 15 on the GHQ scale (Table 3).

$\begin{aligned} & \text { Table 3. Distribution of participants according to GHQ-12 } \\
& \text { score }\end{aligned}$
\begin{tabular}{lll}
\hline GHQ-12 score & N & $\%$ \\
\hline$\leq 15$ & 33 & 49 \\
$16-20$ & 16 & 24 \\
$>20$ & 18 & 27 \\
Total & 67 & 100 \\
Overall $>15$ & 34 & 51 \\
$\chi^{2}=4.157 ; p$-value $=0.04$. & &
\end{tabular}

There was a wide variation in the number of patients seen per day by individual doctors (Table 4). The median number of patients seen was 30, with a range of $12-60$; more than half of the doctors usually consulted with 30 - 50 patients per day. Table 5 shows that none of the doctors who worked less than 30 hours per week was stressed. Table 6 compares the GHQ-12 scores in this study with the findings of Govender et al. among GPs in private practice. ${ }^{17}$

\section{Discussion}

Table 1 shows that doctors from all age groups were represented in the study. This is in keeping with the age distribution of the doctors in the NMM district. The majority of respondents (78\%) were in the age group 26 - 45 years. Work-related stress may particularly affect doctors who have not been practising for many years, but it seems to be prevalent in all age groups in this sample of doctors. This is in keeping reports that modern medical practice is extremely demanding and stressful.' Doctors in general work longer hours than most other workers, and Table 1 confirms that many (47\%) of doctors in our sample work more than 50 hours per week. Other authors have alluded to increased stress in doctors who work longer hours.' However, statistically we did not find a relationship between stress and long hours of work.

In a study of stress among private practitioners by Govender et al., 39\% of participants reported working more than 50 hours per week. ${ }^{17}$ Doctors in our public hospitals therefore appear to work longer hours than GPs in private practice in KwaDukuza. ${ }^{17}$

The doctors in our study did not specify whether the long hours of work they reported (more than is recommended by the Department of Labour) are primarly due to hospital work or afterhours work outside the hospitals. Work overload among medical doctors is not only a South African phenomenon. Cartwright et al., studying workload and stress in UK consultant medical doctors $(N=464)$, found that $56 \%$ were working more than 48 hours a week. ${ }^{18}$

In this study we found no relationship between hours worked per week and number of patients seen per day and level of stress. This 


\begin{tabular}{|c|c|c|c|c|}
\hline \multirow[b]{2}{*}{ No. of patients seen } & & \multicolumn{2}{|c|}{ Overall GHQ-12 score } & \multirow[b]{2}{*}{ Total } \\
\hline & & $\leq 15$ & $>15$ & \\
\hline No response & $\begin{array}{l}n \\
\%\end{array}$ & $\begin{array}{l}4 \\
6\end{array}$ & $\begin{array}{l}3 \\
45\end{array}$ & $\begin{array}{l}7 \\
11\end{array}$ \\
\hline $12-22$ & $\begin{array}{l}n \\
\%\end{array}$ & $\begin{array}{l}10 \\
15\end{array}$ & $\begin{array}{l}6 \\
9\end{array}$ & $\begin{array}{l}16 \\
24\end{array}$ \\
\hline $23-33$ & $\begin{array}{l}n \\
\%\end{array}$ & $\begin{array}{l}5 \\
7\end{array}$ & $\begin{array}{l}10 \\
15\end{array}$ & $\begin{array}{l}15 \\
22\end{array}$ \\
\hline $34-44$ & $\begin{array}{l}n \\
\%\end{array}$ & $\begin{array}{l}7 \\
10\end{array}$ & $\begin{array}{l}7 \\
10\end{array}$ & $\begin{array}{l}14 \\
21\end{array}$ \\
\hline$>44$ & $\begin{array}{l}n \\
\%\end{array}$ & $\begin{array}{l}7 \\
11\end{array}$ & $\begin{array}{l}8 \\
12\end{array}$ & $\begin{array}{l}15 \\
22\end{array}$ \\
\hline Total & $\begin{array}{l}n \\
\%\end{array}$ & $\begin{array}{l}33 \\
49\end{array}$ & $\begin{array}{l}34 \\
51\end{array}$ & $\begin{array}{l}67 \\
100.0\end{array}$ \\
\hline
\end{tabular}

Table 5. Distribution of participants according to number of hours worked per week and overall GHQ-12 score

\begin{tabular}{lllll}
\hline & & \multicolumn{2}{c}{$\begin{array}{c}\text { Overall GHQ-12 } \\
\text { score }\end{array}$} & \\
\cline { 2 - 3 } No. of hours per week & & $\mathbf{5 1 5}$ & $\mathbf{> 1 5}$ & Total \\
\hline$\leq 30$ & $n$ & 3 & 0 & 3 \\
& \% of total & 5 & 0 & 5 \\
$31-50$ & $n$ & 15 & 17 & 32 \\
& \% of total & 22 & 25 & 48 \\
$51-70$ & $n$ & 8 & 8 & 16 \\
& \% of total & 12 & 12 & 24 \\
$71-90$ & $n$ & 5 & 6 & 11 \\
& \% of total & 7 & 9 & 16 \\
$>90$ & $n$ & 2 & 3 & 5 \\
& \% of total & 3 & 5 & 8 \\
Total & $n$ & 33 & 34 & 67 \\
& \% of total & 49 & 51 & 100
\end{tabular}

Table 6. Overall GHQ-12 scores compared with a study in a private setting ${ }^{17}$

\begin{tabular}{lccccc}
\hline & \multicolumn{2}{c}{ Mutunzi et al. (this study) } & & \multicolumn{2}{c}{ Govender et al. $\mathbf{a l}^{\mathbf{7}}$} \\
\cline { 2 - 3 } \cline { 5 - 6 } GHQ-12 score & $\boldsymbol{n}$ & \% & & $\boldsymbol{n}$ & \% \\
\hline$\leq 15$ & 33 & 49.3 & & 16 & 62.0 \\
$16-20$ & 16 & 23.9 & & 4 & 15.0 \\
$>20$ & 18 & 26.8 & & 6 & 23.0 \\
Overall $>15$ & 34 & 50.7 & & 10 & 38.0 \\
Total & 67 & 100.0 & & 26 & 100.0
\end{tabular}

finding is similar to that of Coomber et al., in which there was no difference in terms of hours worked per week and level of stress, ${ }^{19}$ but is in contrast to the results of Govender et al., who found a relationship between long hours worked and level of stress. They found that doctors in private practice who work more hours per week are more likely to be stressed than those who work fewer hours. ${ }^{17}$

Nearly all the doctors (about 90\%) who responded perceive themselves to be stressed at work. This may mean that they are unhappy at work but not objectively stressed as yet, and probably implies that at present they can cope with their working situation and still feel that they are playing a valuable role at work. This percentage is slightly higher than the finding in a similar study, where $78.3 \%$ of participants reported perceiving themselves as being stressed. ${ }^{20}$ These doctors may be at risk of work-related stress and would benefit from stress-relieving and coping strategies before they reach burnout or become totally disillusioned with working as a doctor.

The results indicate that doctors practising in rural district hospitals are just as susceptible to stress as doctors elsewhere. The results may imply that doctors need to be aware of their risk of workrelated problems and stress and need to concentrate on ways to reduce their stress. This would largely involve having other interests or compartments to their lives. ${ }^{8,13}$

The prevalence of stress in this study is higher than that in other studies, which found stress among healthcare workers to be below $50 \%$. The results of Govender et al.'s survey indicated that the prevalence of stress among KwaDukuza GPs was 38\%. ${ }^{17}$ Guthrie et al. found the overall prevalence of stress among psychiatrists to be $31.4 \%,{ }^{20}$ and Lee et al. found $42.5 \%$ of doctors to be stressed. ${ }^{21}$

In terms of level of stress, $26.8 \%$ of our subjects had a very high stress level (morbidly stressed), compared with 23\% reported by Govender et al. (Table 6). ${ }^{17}$ This level of stress is very high and these doctors need psychological intervention as they are vulnerable to burnout and depression. Ramirez et al. found very high levels of stress in $27 \%$ of participants in their study, ${ }^{22}$ and Coomber et al., using the $\mathrm{GHQ}$, also found that $28.5 \%$ of UK intensive care unit doctors scored above the threshold for severe stress. ${ }^{19}$

This study, as well as that of Coomber et al., ${ }^{19}$ did not show any difference $(p>0.05)$ between working hours and stress. This lack of association could be explained by the fact that these public hospital doctors may be stressed not only because of the volume of work they are doing, but by factors like job satisfaction, unhappiness, frustration or other reasons. The analysis of GHQ items confirms this fact and showed that overall 52\% of participants expressed unhappiness with their current job in NMM district.

Thomas and Valli suggested that job satisfaction is a major factor in the risk of work-related stress among doctors. ${ }^{23}$ The majority of doctors in our study (87\%) performed after-hours work and 55\% reported studying after hours as well, which implies that doctors in the NMM district do seem to be overworked. We found that our doctors were more likely to be stressed if they work after hours.

The comparison with findings from Govender et al.'s study ${ }^{17}$ in Table 6 shows that 38\% of GPs scored more than 15 in the GHQ, compared with $51 \%$ of the doctors in our study. Among them, 23\% GPs scored more than 20 compared with $18(27 \%)$ in the NMM study. 


\section{Limitations of the study}

It is almost impossible to conduct scientific research without potential biases during the journey towards the research process. The aim of the researcher is to minimise any potential bias by clear, valid and concise methodology.

There are two possible sources of selection bias in this study. Firstly, NMM district doctors may not be representative of the target population of South African doctors working in public hospitals. Secondly, the respondents may not represent the stress levels of the NMM district doctors as we do not know the psychological/stress status of those who did not respond. Doctors working in the district but not in the public hospitals may not face the same challenges the hospital doctors do, as there are constant emergencies in the hospitals and patients seen there are generally sicker than those attending the clinics. Doctors who work in the clinics usually do not face the challenge of many patients needing to be seen on the same day, and patients are also usually booked at the clinics, so doctors can plan their days. Doctors who work in hospitals are constantly working against the constraints of time and the pressure of emergencies.

The potential sources of bias were minimised by making the study sample statistically powerful (i.e. at $80 \%$ power and $95 \%$ confidence interval). Also, the sample size was enhanced to make the sample as representative of the population as possible. All subjects were assessed by the same researcher, using the same questionnaire. The modified GHQ-12 questionnaire was administered by EM, and the same questionnaire was used to assess stress levels of the participants

\section{Conclusions}

This cross-sectional survey in NMM district confirms that the prevalence of work-related stress among doctors is high and that doctors need to take active measures to reduce their stress.

The doctors of NMM district would benefit from this study by becoming aware of their high levels of work-related stress (51\% of doctors were stressed). The prevalence and level of stress among medical doctors working in NMM district (public sector doctors) were much higher than those among general practitioners in KwaDukuza (private practice). ${ }^{17}$ Doctors who have a perception of being stressed and are not yet objectively stressed (according to the GHQ-12) would benefit most from intervention concentrating on methods of stress reduction and coping mechanisms. Strategies to reduce stress should be implemented among these doctors through the chief director's office. The majority of NMM doctors of would benefit from workshops or other training in techniques, especially those aimed at doctors as part of the caring profession, that may be used to relieve work-related stress. Doctors should also take cognisance of Couper's ${ }^{8}$ suggestion that they need to have other compartments/areas of interest in their lives besides medicine.

\section{References}

1. Grobler C, Hiemstra LA. Stress 1. In the workplace. CME 1998;16(1):19-24.

2. Couper I. Facing and dealing with burnout. SA Family Practice 2005;47(2):3.

3. Selye H. The Stress of Life. New York: McGraw Hill, 1976

4. Di Martino V. The relationship between stress and workplace violence in the health sector Working Paper of the Joint ILO/ICN/WHO/PSI Program on Workplace Violence in the Health Sector. Geneva, 2003. http://www.lo.org/public/english/dialogue/sector/themes/violence.htm (accessed 3 February 2009).

5. Liam V. Moderating the effects of work-based support on the relationship between job insecurity and its consequences. Work and Stress 1997:11(3):231-266.

6. Robbins SP. Organizational Behavior. 9th ed. New Jersey: Prentice Hall, 2001

7. Richards C. The Health of Doctors. London: Kings Fund, 1989.

8. Couper I. Approaching Burnout. SA Family Practice 2005:47(2):5-8.

9. Couper I. How to cope with stress and avoid burnout. In: Mash B, Blitz-Lindeque J, eds. South African Family Practice Manual. 2nd ed. Pretoria: Van Schaik, 2006:379-380.

10. Olkinuora M, Asp S, Juntunen J, Kauttu K, Strid L, Aarimaa M. Stress symptoms, burnout and suicidal thoughts in Finnish physicians. Soc Psychiatry Psychiatr Epidemiol 2004;25(2):81-86.

11. Ross E, Deverell B. Psychosocial Approaches to Health, Illness and Disability. Pretoria: Van Schaik, 2003.

12. Hawton K, Malmberg A, Simkin S. Suicide in doctors: A psychological autopsy study. J Psychosom Res 2004;57(1):1-4.

13. Gaede B. Burnout: A personal journey. SA Family Practice 2005:47(4):5-6.

14. Firth-Cozens J. Doctors, their wellbeing and their stress. BMJ 2003;326:670-671.

15. Goldberg DP, Gater R, Sartorius N, et al. The validity of two versions of the GHQ in the WHO study of mental illness in general health care. Psychol Med 1997;27:191-197.

16. Center for Social Epidemiology. General health questionnaire. http://www.workhealth.org (accessed 2 February 2009).

17. Govender I, Joubert G, Oosthuizen SDW. Stress among general practitioners of Kwa-Dukuza, Kwa-Zulu Natal. African Journal of Primary Health Care \& Family Medicine 2009;1(1). [http:// dx.doi.org/10.4102/ phcfm.v1i1.39]

18. Cartwright K, Lewis D, Roberts C, Bint A, Nicholas T, Warburton F. Workload and stress in consultan medical microbiologists and virologists: a questionnaire survey. J Clin Pathol 2002;55:200-205.

19. Coomber $S$, Todd C, Park G, Baxter P, Firth-Cozens J, Shore S. Stress in UK intensive care unit doctors. Br J Anaesth 2002;89(6):873-381.

20. Guthrie E, Tattan T, Williams E, Black D, Bacliocotti H. Sources of stress, psychological distress and burnout in the psychiatrists: comparisons of junior doctors, senior registrars and consultants. Psychiatr Bull 1999;23:207-212.

21. Lee FJ, Stewart M, Brown JB. Stress, burnout, and strategies for reducing them. Can Fam Physician 2008:54:234-235

22. Ramirez AJ, Graham J, Richards MA, Cull A, Gregory WM. Mental health of hospital consultants: the effects of stress and satisfaction at work. Lancet 1996;347:724-728.

23. Thomas LT, Valli A. Levels of occupational stress in doctors working in South African public-sector hospital. S Afr Med J 2006;96:1162-1168. 